\title{
On sentence-final "what" in Singlish: Are you the Queen of England, or what?
}

\author{
Tania Kuteva \\ Heinrich-Heine University, Düsseldorf \\ kouteva@phil.uni-duesseldorf.de \\ Seongha Rhee \\ Hankuk University of Foreign Studies, Korea \\ srhee@hufs.ac.kr \\ Debra Ziegeler \\ Université Sorbonne Nouvelle Paris 3 \\ dpziegeler@gmail.com \\ Jessica Sabban \\ Heinrich-Heine University, Düsseldorf \\ jessica.sabban@arcor.de
}

\begin{abstract}
This article focuses on one particular linguistic feature of Singapore Colloquial English (SCE), sentence-final what, which has been referred to as an 'objection particle'.

SCE (Smith, 1985:126)

Context: Discussion of a student who is going overseas for one month and will be missing classes.

a. He'll never pass the third year.

b. It's only for one month what.

Sentence-final what in SCE is analyzed in its (synchronic) behavior and (diachronic) development, and the proposal made by the authors is that sentence-final what is a result of a process which started in British English.
\end{abstract}

\section{Keywords}

sentence-final - what - Singlish - Singapore - English 


\section{Introduction}

Our object of investigation in this study is sentence-final what in Singapore Colloquial English (SCE) or Singlish, which is the term commonly used in the specialized literature. As a number of studies have shown already, the primary function of what when used at the end of the sentence in SCE is to mark objection; hence the term proposed for it in the literature, "objection particle".

(1) a. SCE (Smith, 1985: 126).

Context: Discussion of a student who is going overseas for one month and will be missing classes.

A. He'll never pass the third year.

B. It's only for one month what.

(1) b. SCE (3/10/16, personal observation)

Context: Discussing the topic of A's brother travelling to Singapore:

A: He probably hasn't got much money.

B: But going to Singapore doesn't cost very much what!

Smith (1985) describes the above use of sentence-final what in SCE as an emotive particle, which-in addition to its fixed position at the end of the sentence-exhibits the following two characteristics: Intonation drop plus low pitch, and indication that the speaker objects to something in the context. In (1b), B uses what to refute what is assumed in the context of A's commentthat it is expensive to travel to Singapore.

It is our goal here to unravel the mystery of this "weird" use of what in SCE as an emotive particle. More precisely, our ambition is to explain the synchronic behavior of SCE sentence-final what in terms of its diachronic development. For this purpose, we will situate it in a more global picture-or a semantic map - of uses of interrogative what across languages.

In previous studies sentence-final what in SCE has been treated as the result of language transfer from the local, substrate languages, for example, Hokkien Chinese, Cantonese, etc. The present proposal radically differs from existing analyses: The standpoint we take here is that SCE sentence-final what originated in the lexifier (non-local) language, British English. We propose that SCE sentence-final what is a linguistic expression that resulted from a process which has its origins in British English and went further on in SCE.

In Section 2 we will describe the major uses of sentence-final what in SCE from a synchronic perspective, whereas Section 3 will take a diachronic perspective on it. In Section 3 we will also argue that SCE sentence-final what 
can be placed within a functional network of the interrogative pronoun what identifiable across geographically and genetically related und unrelated languages. Section 4 will then present the conclusions of the present study.

A perusal of the literature on sentence-final what in SCE reveals the following four primary functions of this particle: Objection, discontent, (appeal for) agreement/solidarity, and mitigating one's own assertion.

\subsection{Objection}

The example below is a manifestation of sentence-final what functioning as a marker of objection, whereby person B objects to person A's doubt that the example they are discussing might not be authentic.

(2) a. SCE (Smith, 1985: 127).

Context: Discussion between the writer $\mathrm{A}^{1}$ and a Singaporean colleague $\mathrm{B}$ of some examples of the usage of what which she has supplied.

A: If this is a REAL example=

B: =It Is what. ${ }^{2}$

(2) b. SCE $(27 / 9 / 16$, personal observation)

Context: Stopping the car at a set of traffic lights that the speaker had previously thought were not working:

A. Still working what! Who said they weren't working!

\subsection{Discontent}

The example that follows does not involve as vehement an objection as the previous one. What it expresses is rather discontent, which may, it seems to us, come close to a contemptuous reminder of shared knowledge. ${ }^{3}$ Smith (1985: 111) explains the use of sentence-final what in this particular example as: "Here the secretary brands the student's request as unjustified, since there are thumb tacks available at the notice board. There is in addition the implication that the

1 Ian Smith, the author of one of the most insightful studies of SCE sentence-final what, which involved collecting examples of authentic speech production in SCE; TK/SR/DZ/JS.

2 The capitalization of Is here indicates that this word is stressed.

3 This may be discourse world knowledge, or general world knowledge. 
student should know this and therefore should not have felt necessary to ask in the first place".

(3) SCE (Smith, 1985: 111)

Context: A student wants to post a notice on the notice board.

Student: Can I have some pins ah?

Secretary: Notice board got pins what.

\subsection{Appeal for Agreement/Solidarity}

A large number of examples with sentence-final SCE what show that this particle marks an appeal on the part of the speaker to the hearer for agreement. ${ }^{4}$

(4) a. SCE (Platt, 1987:399)

Not bad what, the show?

(4) b. SCE

$\mathrm{H}^{* *} \mathrm{~L}^{* * * *}$ no good meh ? quite a nice place what, no ?5

(http://forums.hardwarezone.com.sg/printthread.php?t=173369o\&pp= 5o Posted by: Oreo_Cheescake V2.0 19-05-2008 05:17 PM)

Whereas in the above example by using what at the end of the clause the speaker invites the interlocutor to assent, in the following example it is rather the expression of solidarity on the part of the speaker with what the interlocutor has just said (cf. also the analysis proposed of this example in Smith, 1985: 110): “What here can be glossed as 'You're telling me!' or 'Don't I know it!".

(5) SCE (Smith, 1985: 110).

A: Very hot today.

B: Ya what! I'm nearly melting.

\section{$2.4 \quad$ Mitigator}

In some contexts, SCE sentence-final what functions as a means to tone down, or subdue the speaker's own statement. In such cases, it could be paraphrased by means of an expression meaning "I think/in my opinion".

4 As Bernd Heine (p.c.) points out to us, this use of what is very much like the use of a tag question marker.

5 Presumably, $\mathrm{H}^{* *} \mathrm{~L}^{* * * *}$ is text-talk abbreviation for 'hell'. Meh is another discourse marker used to express uncertainty. 
(6) a. sCE (Platt, 1987: 399)

A: Have you been to the restaurant?

B: Yes, the food there is not bad what.

(6) b. sCE

Not bad what! I would say the quality of the painting is almost up there with the Eavy Metal team! Really nicely done! (http://forums.relicnews.com/showthre... $=190505 \&$ page $=2$ Posted by: seow_lang 30-10-2008 07:55 PM) ${ }^{6}$

Notice that what may occur in this function of a mitigator also in what Smith (1985: 114) refers to as a "prophylactic" use, whereby the speaker-in anticipation that she will be questioned on her statement-uses what in order to justify her position "in advance". Thus Smith (1985: 114) describes the following example as involving a speaker who "protects his position by branding any misgivings at the prospect of bankruptcy as unjustified".

(7) SCE (Smith, 1985: 113)

Context: A talk on starting your own small business (Straits Times 12 June 1982).

Speaker: Once you're in business, there is no security, only opportunity. The worst that can happen to you is you become bankrupt. But never mind what, it's not a crime to be bankrupt.

In addition to these four functions one can also find what Kwan-Terry (1978) refers to as "anger/irritation", which she considers to be one of the most common functions of SCE sentence-final what (cf. also the term used in Smith, 1985: 113, "self-righteous indignation"). In the present study we do not treat anger, irritation, and self-righteous indignation as a function distinct from the first two functions pointed out above, objection and discontent. Rather, we assume these emotional nuances to be present in the contexts of use of what as objection marker and as a discontent marker to a varying degree depending on the emotional load of the context.

We do recognize, however, a fifth major function of SCE sentence-final what, which we propose to call emotional emphasis and for the sake of convenience will refer to as emphasis. In its emphatic function sentence-final what is not characterized by either positive or negative polarity as inherent part of its

6 The internet data are taken from a corpus of Singapore chat-room postings compiled between 2008-9; some of the original threads may no longer be accessible. 
meaning. Its function is precisely to emphasize whatever information is conveyed by the preceding linguistic expression.

\subsection{Emphasis}

The following example illustrates the use of sentence-final what as an emphatic particle.

(8) SCE (Smith, 1985: 113,124)

Context: $\mathrm{C}$ is ill.

A: Then have you seen the doctor or not? ... What did she say?

B: Nothing ah?

C: I tell you the doctor sees me: I tell her everything, that's all. ... True what. They don't know what's wrong with you. You got to tell them first right?

Our major goal in this study is to reconstruct the historical scenario of development that led to the objection particle what in SCE. In the existing literature this particle has been commonly treated as the result of the language contact situation characterizing SCE. SCE is the colloquial variety of Singaporean English, which is now a nativized, contact dialect of English, with the current generation of speakers having acquired the language from infancy. In descriptive terms, it is the local vernacular, $\mathrm{SCE}$, that has most contributed to the richness of the linguistic contact features under analysis in much of the literature; the standard counterpart variety, Singapore Standard English (SSE), is generally held to be little different from any other international standard English variety (see e.g. Gupta, 1994). As well as English, the present generation of Singaporeans is in daily contact with Mandarin Chinese, which has been promoted and prescribed as the standard Chinese lingua franca to be used amongst Chinese citizens of various Chinese dialect backgrounds, via the government's "Speak Mandarin Campaign", initiated in 1979. Mandarin Chinese has therefore been replacing the southern dialects of Chinese (mainly Hokkien or Southern Min, Cantonese, Teochew, and Hakka) in their typical local communities since the 1980s (Ho, 1986: 15). As a result, it is expected that English and Mandarin will undoubtedly influence one another in daily contact situations. Other languages spoken in the region, such as Bazaar Malay, Baba Malay, Tamil, and other Indian minority languages have also been shown to have influenced Singaporean English, as evidenced in Begum and Kandiah (1997). Gupta (1994) and Ho and 
Platt (1993), amongst others, consider this influence, though, to be less significant than the Chinese dialects, as their speakers are fewer in number (less than $30 \%$ of the entire population).

Since Singapore was a British colony up until 1963, whereby Bazaar Malay and Hokkien Chinese were the lingua francas in the early $20^{\text {th }}$ century and English was only spoken among the very upper class and British colonial masters, it is not surprising that there have been accounts of the origins of the SCE objection particle what in terms of borrowing from the local, non-lexifier languages. "In fact, there has been a tendency ... for researchers to identify the structures [the sentence-final emotive particle what being one of them, $\mathrm{TK} / \mathrm{SR} / \mathrm{DZ} / \mathrm{JS}$ ] as coming from the languages they happen to be most familiar with" (Gupta, 1992: 34). Thus, for the origins of SCE sentence-final what several proposals have been made in the literature, all of which involve transfer (indirect diffusion, calque) from the use of emotive particles in the local, contact varieties, where the following varieties have been regarded as the source of linguistic transfer.
(9) a. Mandarin, Hokkien and Cantonese Chinese (Kwan-Terry, 1978)
b. Hokkien and Cantonese (the emotive particle $m a$, cf. Smith, 1985)
c. Bazaar Malay and Hokkien Chinese (Lim, 2007)
d. Tamil (Baskaran, 1988).

What underlies all these hypotheses is the argument that SCE has quite a large inventory of particles, all of which have been borrowed from some southern variety of Chinese dialects or other regional languages; hence, it should be unlikely that sentence-final what came from English; rather it, too, should have come either from a Chinese dialect or some other regional variety. The logic behind this argument is that "what has been repeated many times is most likely to be repeated again".

There are several objections, we argue, that can be made to this logic. First, just as it is true that "what has been repeated many times is most likely to be repeated again", it is certainly also true that "there is a first time for everything". Thus it is a well-established fact that occasional items from colonial British usage have actually entered the language and certain "markers" of learned colonial usage have certainly become entrenched, for example, "to pluck (fruit from a tree)", "to purchase" - said with a diphthong instead of a schwa on the second syllable, instead of "to buy". Similar items have been observed by Ho and Platt (1993: 148). 
Second, a closer look at the particular pragmatic particles that have been borrowed from southern Chinese dialects and other regional varieties into Singapore English reveals that whereas it is very plausible to assume borrowing as the cause for the existence of most pragmatic particles in SCE, there exists one particle where such an explanation is in need of modification, and it is precisely sentence-final what. This becomes clear when what is considered as part of the whole set of pragmatic particles in SCE. Lim (2007: 1) gives the following list of pragmatic particles which are well-documented in Singapore English: ah, hah, what, lor, hor, nah, leh, ma, and meh.

What is striking about this list is that what is the only pragmatic particle with a phonological form which comes from colonial usage, that is, British English interrogative what. All other particles are clear instances of adoption of form-meaning pairings from the contact language varieties, that is, they comply with the textbook definition of the term borrowing in a narrow sense as "the adoption by one language of sounds or form-meaning pairings (e.g. morphemes, words, or larger units) from another language" (Kuteva, forthc.). ${ }^{7}$ Against the backdrop of this comparison, it is most likely that the colonial lexifying language, British English, had a mediating role - to say the least—in the genesis and evolution of this emotive particle in Singapore Colloquial English. It is indeed very plausible to assume that it comes from the lexifier even if the substrate language varieties may have also exerted some influence, since they, too, have sentence-final particles with similar functions.

The strongest argument in favor of this scenario, however, comes from a careful diachronic study of sentence-final use of what in British English. The reason why an account centered around British English as the Model Language for SCE sentence-final what might seem counter-intuitive at first sight most likely has to do with the following fact: In present-day British English, sentence-final use of what seems to be acceptable only in very restricted types of context like the following example (taken over directly from Smith's 1985

7 As a matter of fact, it has been hypothesized in the literature that SCE sentence-final what is a borrowing - in the narrow sense - from Cantonese, the reason for this being the resemblance between SCE what and Cantonese wo as well as the "partial overlap in function" (Gupta, 1992: 42). This hypothesis, however, is implausible since SCE what has a central open unrounded vowel and often an unreleased dentalized alveolar stop as coda in contrast to Cantonese wo, which is a "mid back rounded vowel with no coda" (Lim, 2007: 464). Moreover-even though SCE what and Cantonese wo have been referred to as near-homophones-in terms of function they are more different than similar, for the following reason: Cantonese wo simply expresses "noteworthy discovery" (Lim, 2007:464). 
study and presented to native speakers of English) with what functioning as a marker of appeal-for-agreement/solidarity.

(10) British English (Smith, 1985: 128, judged as perfectly acceptable also for present-day British English, Brian Hicks, p.c.)

Context: Interview with a national serviceman. He has said that he doesn't think that two children (the limit encouraged by the government) are too few and expresses willingness to pay even a $\$ 1000$ fine to have more.

Interviewer: Won't you be angry with the government for being so unreasonable?

NSman: No. ${ }^{8}$ What for? The government wants to reduce population what!

The other type of context that allows for a sentence-final use of present day British English what involves its use as an emphatic marker. The following example contains two uses of what at the end of the sentence. Whereas the first one seems to result from an omission of the larger part of a whole clause something like ... "what you/we should do" (as part of the complex sentence "I tell you what you/we should do") whereby only the initial word, what, remains, the second sentence-final what - marked in bold in the example below-functions as an emphatic marker.

(11) Colloquial British English (Davies, 2004-)

A: No, I haven't even heard the rest of the songs. I tell you what.

B: Yeah.

A: I'll let you listen to it, I brought it in today. Rough tape what.

It is the same function that what has when used as a tag at the end of a sentence in present-day English, especially in posh pseudo-upper-class British use. Thus, when what is a tag in a sentence like "It's a nice day, what?", it is reinforcing rather than questioning. Further examples of the same use would be "It's a lovely day, what?", or "She is a real beauty, what?", or "He acts like a scoundrel, what?" (Robert M.W. Dixon, p.c.).

8 Notice that in the original SCE text there is a particle, la, following $N o$, that is, the speech act begins with No la. The reason why there is no la in the example discussed here is that it constitutes the British English version of the SCE original example, and in British English there is no la. In other words, this utterance was presented to a British English native speaker and the presence of la would have influenced his judgement. 
The mitigator, the discontent and the objection uses of sentence-final what are either archaic or simply nonexistent in present-day British English. Thus the example below with SCE sentence-final what marking discontent/objection can only be interpreted by native speakers of British English as meaning “... or what do you think?", that is, in its original, interrogative function.

(12) British English (Smith, 1985: 114, described as expressing discontent in SCE because of the obviousness of the shared information between speaker and hearer but judged as asking an honest question by native speakers of British English, paraphrasable as “... (or) what do you think?”, Brian Hicks, p.c.)

Context: The Singapore Armed Forces are generally seen as a breeding ground for "slang" and "bad language".

A: His language is terrible!

B: Army what! ${ }^{9}$

Whereas in present-day British English sentence-final what is rather infrequent in use, if we take a diachronic perspective we observe a variety of uses of what which differ from its original interrogative use at the beginning of an interrogative clause, even though to a varying degree.

First, we observe that there are examples of what as a stand-alone word in pre-mid-nineteenth century British English, that is, in the pre-contact situation, prior to the foundation times of the SCE variety. In such examples what is used on its own (often preceded by "eh!") in contexts involving emotional emphasis, and accordingly its punctuation consists of an exclamation mark rather than a question mark. In such examples what! is no longer an interrogative marker but rather an emotive particle. This is indicated - in some examplesby its co-occurrence with entire interrogative clauses beginning with what in its source (i.e. interrogative) function, so that at this stage one can talk of "division of labor" between interrogative what and emotive what.

(13) British English (Morton, 180o)

Sir Abel. Eh! What!—what's that—Eh! what do you mean?

9 Notice that in this particular example, the use of what is equivalent to one of a retrospective explanatory comment on any preceding information in the discourse; for example in (12): "Army—-that's why!", or "That's because of the army!"; that is, it expresses a sense of justification. This is felt by some native speakers to be perhaps the most frequent function of what (pronounced wut) in Singlish (Tuck Choy, personal communication). 
Such examples show - we propose - that by the end of $18^{\text {th }}$ century what had moved away from its original interrogative meaning in the direction of emotive meaning. It seems to be only a small syntactic step from an independent use of what following a preceding linguistic expression to a concatenation of that expression with a free-standing what (sometimes preceded also by "eh!") within the contour of a single sentence, with what being used sentence-finally.

A careful diachronic study reveals indeed that with the exception of the objection function all the other functions of SCE sentence-final what have been attested at a stage of the development of British English prior to the foundation time of the SCE variety. These functions of the mitigator, appeal for agreement/solidarity and discontent can be identified in the following examples, all of which pre-date the formation of SCE.

Mitigator

(14) British English (Hoare, 1796)

Brum. Oh, oh, my dear friend, but what!-All this happen before the father's face!

Appeal-for-agreement/solidarity

(15) British English (Butler, 1716)

Make thy self worthy to be my Successor [sic]; what?

Discontent

(16) British English (Lennox, 1756)

I have lost you then a second Time [sic] my dear Adelaida (cried I) and I have lost you for ever, what!

From the context of the example above it becomes clear that the speaker who produced the utterance grieves for Adelaida. What also becomes clear is that the sentence-final use of what here marks emotional emphasis intertwined with discontent with the situation in which the speaker finds himself, involving a lot of grief and bewilderment in this particular case.

A similar use of sentence-final what in British English involving strong emotionality comes from an even earlier example from the beginning of the eighteenth century.

(17) British English (Butler, 1716)

... you've found the only means, next to your hating me, that could undo my peace, you almost tear my Heart [sic] up by the roots; what! 
The utterance may consist of an initial statement-like in the above examples-but it may just as well be an order. What matters is that there is emotional overload expressing some kind of discontent with something in the discourse situation, as the following example from the end of the eighteenth century shows.

(18) British English (MacNally, 1781)

This is undoubtedly a predetermined scheme to affront magistracy, said my Lord Praetor — bring the rascals before me — what!

Emphasis

(19) British English (O'Keeffe, 1795)

Yes, it is my wish; what! Martha will convey me privately into the Castle [sic]? delightful[sic]!

Notice that the same four functions-mitigator, appeal-for-agreement/ solidarity, discontent, and emphasis - of sentence-final what are still to be recognized in the British English variety contemporaneous with the emerging SCE variety, that is, after the mid-nineteenth century as the examples below indicate.

\section{Mitigator}

(20) Modern British English (oED 1914 A.M.N. Lyons Simple Simon i. i. 16) ${ }^{10}$

Can't say I've read it. It's a bit too literary for me. What?

But they say it's jolly clever. You had it at school, I dare say. What?

In (20) it is only the first use of what-marked in bold — that functions as a mitigator (paraphrasable as "I think/in my opinion, at least/I dare say"), the second what has the function of appealing for agreement/solidarity (paraphrasable as a tag question “..., don't you think?”).

Appeal-for-agreement/Solidarity

(21) Modern British English (oED 1906 C. Mansfield Girl and Gods xvi)

Good-bye, Miss Thornton, awfully jolly evening — what?

$10 \quad$ "what, pron., adj.1, and adv., int., conj., and n... oed Online. Oxford University Press. Online: http://www.oed.com/viewdictionaryentry/Entry/228078. 
Discontent ${ }^{11}$

(22) Modern British English (OED 1891 J.S. Winter Lumley Xv. 110)

But she's so beastly chic, dontcherknow-eh, what!

Here (eh,) what! functions as a reminder of something which is obvioushence the use of the fixed collocation dontcherknow - and it is the obviousness of the fact expressed in the preceding clause that causes the discontent on the part of the speaker. Notice that this may well be ambiguous. It seems also likely that there is an appeal for agreement here, especially in the use of dontcherknow.

\section{Emphasis}

(23) Modern British English ${ }^{12}$

Damn fine shooting, what!

Bearing the above arguments in mind, in the present study we propose an account which radically differs from the accounts existing in the literature of the rise of sentence-final what in SCE. On the present proposal we regard it as the continuation of a development which started in the nonlocal, lexifier language, British English. ${ }^{13}$

In what follows we will build a case for a four-stage development of what to be traced back to the foundation time of the SCE dialect:

Stage o: interrogative question (INT)

Stage I: rhetorical question of discontent ( $\mathrm{RH}$ Dis.)

11 When used sentence-initially in what Dixon (2015) calls a "special exclamation construction" (which he employs as one of a number of litmus tests to identify a distinct set of forms for English pronouns), it seems that discontent/disgust is a well-established use of what in Modern English, for example, "What, me be made to clean up and not you!" or "What, me!"

12 T. Sharpe-Seadict. Online: http://www.seadict.com/en/en/what.

13 It has been argued in the literature (e.g. Gupta 1998) that British English was not the only input lexifier for Singapore English. However, it cannot be denied that its presence was significant in the colonial situation, and that certain usages in Singapore English may be traced to sources in the dialects of the colonial masters. Even the positive use of the adjective damn in (23) to express admiration in upper-class British English, for example, is replicated in SCE today: Saw lotsa people wear boots nowadays, damn stylo (http://www .flowerpod.com.sg/forums/index.php?showtopic=22714andst=16o $($ o1/07/08)). 
Stage II: discourse marker of discontent (Dis. DM)

Stage III: objection marker (овJ).

We will argue that the most advanced stage of this development (Stage III, OBJ) appears to have only been reached in SCE, but not in British English. More generally speaking, the scenario we hypothesize for the development of the SCE objection particle what is summarized in Fig. 1.

Interrogative Question $\rightarrow$ Rhetorical Question $\rightarrow$ Discontent Marker $\rightarrow$ Objection Marker

FIGURE 1 Functional development of ScE objection particle what.

We will show that the sequence of stages in Fig. 1 is one branch (the lowest one in Fig. 2 below) of what we will call a polyfunctional development of the interrogative pronoun what, which can be identified across genetically related and unrelated languages.

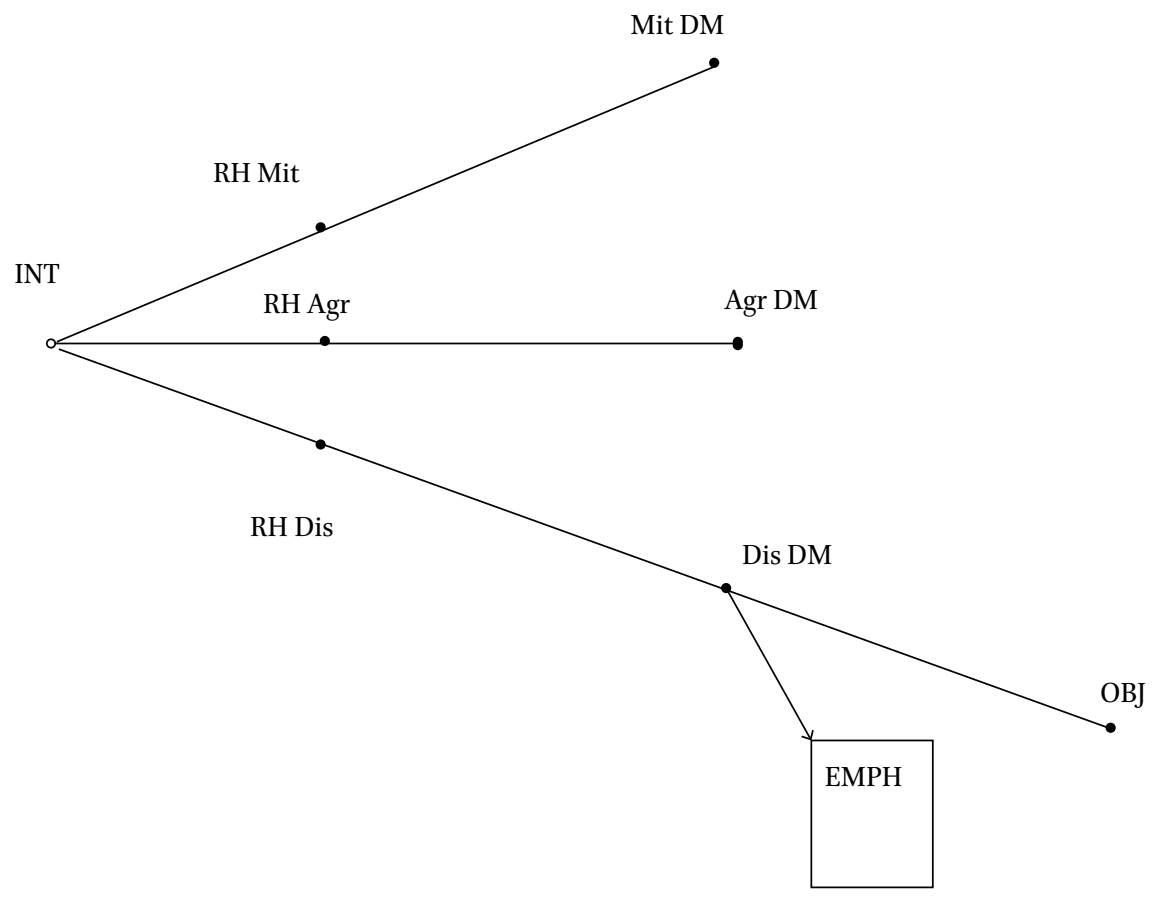

FIGURE 2 Polyfunctional development of what across languages.

In the following subsections we will take a closer look at each of the three branches represented in Fig. 2. 
Stage o constitutes the beginning point for all three branches of the polyfunctional development what has undergone. This is the stage of interrogative clauses beginning with what and can be exemplified by a simple question.

(24) English

What do you think?

At this stage what is used in the beginning of honest, information-seeking questions. Such questions are usually characterized by a pause that would enable the hearer to respond, an interrogative intonation contour, and no syntactic embedding.

Stage o can be assumed to be universal since all world languages are assumed to have interrogative clauses with the equivalent of a $w h$-word.

At the following stage, Stage I, some discourse-sensitive interrogative clauses come to be used as rhetorical questions. Recall that even when they are marked as questions, rhetorical questions are not intended to be questions in that neither the speaker expects an answer, nor does the hearer feel obliged to provide an answer (Rhee, 2004a,b; Herring, 1991).

The specialized literature discusses three major rhetorical strategies: mitigating an assertion, expressing (or appealing for) agreement/solidarity, and expressing discontent. It is the first of these that is relevant for the branch of the polyfunctional development under discussion in this section, hence we will turn to $\mathrm{RH}$ Mit. first. These are used to tone down the assertive force of an utterance (Rhee, 2004a,b). The following example-characterized by a noninterrogative intonation contour of the final clause (as well as the generic use of you)_can illustrate this for English.

(25) British English (Charlotte Hemings, p.c.)

A: Oh, did you know there's more vitamin $\mathrm{C}$ in blackberries than in oranges?

B: Oh, that can't be true, can it?

A: Yeah, I learnt it today, at school.

B: Well, what do you know (= it's true).

Notice that the word for what is used at the beginning of $\mathrm{RH}$ Mit. in other languages as well as shown in the following examples from Bulgarian, German, and 
Korean. Notice also that in all three examples the what word is part of a fixed expression which does not have an interrogative intonation contour.

(26) Bulgarian (non-interrogative contour, fixed expression; generic)

\begin{tabular}{|l|l|l|l|l|l|l|l|l|}
\hline Vsički & tezi & politici & sa & korumpirani, & kakvo & da & se & pravi.(!) \\
\hline all & these & politicians & are & corrupt & , what & CONJ.PTCL & REFL & do $^{14}$ \\
\hline
\end{tabular}

'All these politicians are corrupt, what can you do. (!)'

(27) German ${ }^{15}$

Context: Y (male) and Z (female) talk about the fact that they have reached their destination too early.

Y: Was ne kacke. guck mal wie früh wir da sind:/

Z: Ja was sollen wir tun.

Z: Geht nicht anders.

Y: Jaaaa

\begin{tabular}{|l|l|l|l|l|}
\hline Ja & was & sollen & wir & tun. \\
\hline yes & what & should & we & do. \\
\hline
\end{tabular}

'Yes, what are we supposed to do.'

"[W]as sollen wir tun" in the German example is a mitigating rhetorical question. $\mathrm{Z}$ tries to calm down $\mathrm{Y}$. The message $\mathrm{Z}$ wants to get across is: "Cheer up! We had no choice. We were forced to arrive here that early." She does not want Y to respond. She comments on her own previous statement "Ja was sollen wir tun" immediately by saying "Geht nicht anders": There is no other option.

Another example of a rhetorical question of mitigation in German can be seen in the utterance below, where the use of the indefinite pronoun man as part of the clause "Was will man machen" is indicative of lack of personal

\footnotetext{
14 COMP: complementizer; Fut: future; HORT: hortative; NOM: nominative; NOMZ: nominalizer; Q: interrogative; SFP: sentence-final particle; SFPD: sentence-final particle of discontent; TOP: topic.

15 SMS-Datenbank (LINSE) Universität Duisburg-Essen; SMS-Dialog \#3022—Feststellung (Kategorien: Informationsaustausch). Online: https://www.uni-due.de/ hgo263/SMSDB/ ? site $=$ anzeige $\&$ id $=3022 \&$ highlight $=$ was.
} 
responsibility for a bad situation and therefore mitigation of the statement about the gravity of the situation.

\section{(28) German ${ }^{16}$}

Context: A monologue.

Aber die Verhältnisse sind oft stärker, als unser [sic] Wille.Was will man machen! Ein paar Mißernten [sic] und dann die Hypotheken, mein Lieber! die [sic] Hypotheken!

\begin{tabular}{|l|l|l|l|l|l|l|l|l|l|l|l|l|}
\hline Aber & die & Verhältnisse & sind & oft & stärker, & als & unser & Wille. & Was & will & man & machen! \\
\hline But & the & Circumstances & Are & often & stronger, & than & our & will. & What & want & one & do! \\
\hline
\end{tabular}

'But the circumstances are often stronger than our mental strength. What can one do!'

Here the speaker is unhappy about the situation, but it seems that at the moment nothing can be done. This aspect is closely related to the fact that the speaker does not expect a response which in turn is supported by means of the exclamation mark at the end of the rhetorical question. It is clear that nothing can be done. It is a very hard time. Financial pressure makes it impossible to act differently. You cannot do anything about it. And you should not be blamed for it, because you are forced to live in times of debts and an extremely bad harvest.

Rhee (2004b: 416) describes the use of a fully conventionalized rhetorical question in Korean involving the interrogative mwe 'what', used as a mitigator, that is, a usage motivated by the speaker's intention of reducing the assertive force.

(29) Korean (Rhee, 2004b: 416)

$$
\begin{aligned}
& \text { mwe-la-l-kka } \\
& \text { what-COMP-FUT-Q }
\end{aligned}
$$

16 Digitales Wörterbuch der deutschen Sprache; Treffer 1 (Deutsches Textarchiv) Polenz, Wilhelm von: Der Büttnerbauer. Berlin, 1895. Online: http://www.dwds.de/?view=1\&qu= $\% 22$ Was+will+man+machen $\% 3 \mathrm{~F} \% 22$. 
Now, RH Mit. may further develop into DM Mit., whereby some (or all of the) words following what may be omitted, compare the following example of the so called "prophylactic use" of sentence-final what in SCE.

(30) SCE (Smith, 1985:113)

Context: The conclusion of an explanation or exposition.

A: So simple what.

Here the Speaker "anticipates being questioned on what he is saying" and "may use what to try to protect his/her position" (Smith, 1985: 113). This usage has also been observed by Wong (2004).

This we observe not only in SCE but also in languages which are very distant both geographically and genetically from it. Thus, in Korean a RH Mit. eroded to a sentence-final what discourse marker.

(31) Korean (Rhee, 2004a: 119)

\begin{tabular}{|l|l|l|l|l|}
\hline kuke-n & pyelo & an & coh-untey, & mwe \\
\hline it-TOP & particularly & not & good-sFP & what \\
\hline
\end{tabular}

'It doesn't seem to be so good (to me)' (Lit. 'It is not particularly good, what.')

In Bulgarian, too, there is a mitigating expression kakvo sega! (lit. 'what now') where the what word is re-enhanced by the temporal adverb sega 'now'.

(32) Bulgarian

\begin{tabular}{|l|l|l|l|l|l|l|l|l|}
\hline$I$ & tja & $n e$ & $e$ & $v$ & părva & mladost, & kakvo & sega! \\
\hline And & she & not & is & in & first & youth, & what & now \\
\hline
\end{tabular}

'She is not particularly young either, I daresay.'

In present-day British English the use of sentence-final what as a mitigating discourse marker is not easy to find. As for American English, the situation remains unclear to us. On the one hand, it is possible to find examples in the Contemporary Corpus of American English like the one below where what at the end of the sentence seems to manifest this use. 
(33) American English (Davies, 2008-, COCA)

John Donavan: Wait. Let me stop you there. When you say it's easy, you mean being single-doing it on your own is easy-is that what you're saying.

Jane: Well, it's easier than having somebody else to fight with, what. ${ }^{17}$ When somebody — when two people decide to have a child together, they should be sitting down ahead of time and talking about how they're going to raise the child ...

On the other hand, our informants on American English all agree that such a use of sentence-final what does not belong to "authentic" American English speech; rather it is an imitation of posh British English.

\subsection{Interrogative Question $\rightarrow$ Rhetorical Question of Agreement $\rightarrow$ Discourse Marker of Agreement $($ INT $\rightarrow$ RH Agr. $\rightarrow$ DM Agr.)}

This branch of the polyfunctional development of what starts from Stage owhich has been described already in the previous subsection - and continues with the stage of rhetorical questions of appeal for agreement/solidarity. This type of rhetorical questions express old or otherwise accessible information, an aura of solidarity or a presupposition of the hearer's agreement as the following (constructed) example in English shows.

\section{(34) English}

Context: A student is being called to the school principal's office to be told about his punishment for bad behaviour. The school principal restrains himself from the harshest punishment possible and goes for milder consequences:

Principal: I won't have you expelled from school, you'll have to apologize to your classmates instead, what could you possibly say to that?!

This use of what at the beginning of rhetorical questions of agreement/solidarity can also be observed in other languages, as the use of the clause "was will man mehr" in the utterance below illustrates.

17 Notice that-after listening to this piece (http://www.npr.org/2012/02/27/147514071/ op-ed-it-seems-easier-to-raise-a-kid-alone) - one of our referees points out he is convinced that what is the correct transcription here. 
(35) German ${ }^{18}$

Context: Dialogue about politics between two characters (St. Real and his addressee).

Ein guter Untertan, lieber St. Real, findet sich in Alles [sic]. Der liebe Gott wird's zum Guten fügen, und das Genie unserer großen Staatsmänner, und wir haben einen guten König; was will man mehr ! Apropos, was halten Sie von unserm [sic] König?

\begin{tabular}{|l|l|l|l|l|l|l|l|l|l|}
\hline und & wir & haben & einen & guten & König; & was & will & man & mehr! \\
\hline and & we & have & a & good & king; & what & want & one & more! \\
\hline
\end{tabular}

'and we have a good king; what more could we want!'

This utterance involves a rhetorical question of agreement/solidarity because it is interpreted by native speakers of German as the linguistic expression of something like: "We have a good/great king. So don't worry. I know you will agree with me, we could not be asking for more. We are in a good position."

At a further stage of development, some rhetorical questions presupposing appeal-for-agreement/solidarity may develop further into appeal-foragreement/solidarity discourse markers as has in fact happened in Tamil, Telugu, and German.

(36) Tamil (Lakshmi Bai, 1991: 203)

\begin{tabular}{|l|l|l|l|}
\hline Naan & paticcuttu & tareen & enna \\
\hline I & having read & will give it & what \\
\hline
\end{tabular}

'I will finish reading it and give it to you, O.K.?'

(37) Telugu (Lakshmi Bai, 1991: 203)

\begin{tabular}{|l|l|l|l|}
\hline Nuu & saayintram & raavaali & eenti \\
\hline You & in the evening & should come & what \\
\hline
\end{tabular}

'You must come in the evening, O.K.?'

18 Digitales Wörterbuch der deutschen Sprache; Treffer 2 (Deutsches Textarchiv). Alexis, Willibald: Ruhe ist die erste Bürgerpflicht oder Vor fünfzig Jahren. Bd. 1. Berlin, 1852. Online: http://www.dwds.de/?view=1andqu=\%22Was+will+man+mehr\%3F\%22. 
(38) Spoken German

\begin{tabular}{|l|l|l|l|l|}
\hline Nicht & schlecht & die & show, & was? \\
\hline Not & bad & the & show & what \\
\hline
\end{tabular}

'It was/is not bad, the show, right?'

Meshtrie (1982: 108) gives the following example of the same use of sentencefinal what in South African Indian English, and writes: "In emphatic, rhetorical styles what is used in final position as interrogative marker, indicating an expected negative answer."

(39) South African Indian English (Mesthrie, 1982: 108)

You din [sic] hear me, what? (= Didn't you hear me?)

The following example comes from spoken French:

(40) Spoken French (Beeching, 2002: 293)

On ne va pas se brouiller, que diable! Errare humanum est, quoi!

'We're not going to fall out, damn it! Errare humanum est, after all!'

Here is how Beeching (2002: 293-294) comments on this example: "a reinforcement of the appeal inherent in 'Let's not fall out!' ... The speaker provides further justification for his initial speech act, emphatically punctuated by quoi. Quoi constitutes an appeal to the interlocutor to accept the speaker's argument."

Similarly, Korean has a rhetorical question that developed further into a discourse marker of appeal-for-agreement/solidarity.

(41) Korean

Context: A and B are in a hurry and A is considering jay-walking. A:

\begin{tabular}{|l|l|l|l|l|l|}
\hline kunyang & kenne-ca. & Amwu-to & an & po-nuntey, & mwe. \\
\hline just & cross-HORT & anyone-even & not & look-SFP, & what \\
\hline
\end{tabular}

'Let's just cross (the street). No one's watching (us), what.' 
(42) Korean ${ }^{19}$

Context: A failed an entrance exam to a medical school and implores the administrator B to allow him to audit the class and work as an assistant to the dean. $\mathrm{B}$ is refusing the request.

\begin{tabular}{|c|c|c|c|c|c|c|c|c|c|c|c|}
\hline Ceng & uysayng-i & $\begin{array}{l}\text { toy-ko. } \\
\text { siph- } \\
\text { umyen }\end{array}$ & $\begin{array}{l}\text { naynyen- } \\
\text { ey }\end{array}$ & $\begin{array}{l}\text { ppop- } \\
\text { ul-ttay }\end{array}$ & tasi & $\begin{array}{l}\text { ungsiha- } \\
\text { myen. } \\
\text { toy-ci }\end{array}$ & mwe. & Kkok & olhay-i-l & philyo-ka & iss-na? \\
\hline Really & $\begin{array}{l}\text { medical. } \\
\text { student- } \\
\text { NOM }\end{array}$ & $\begin{array}{l}\text { become- } \\
\text { want-if }\end{array}$ & $\begin{array}{l}\text { next. } \\
\text { year-at }\end{array}$ & $\begin{array}{l}\text { select- } \\
\text { ADN- } \\
\text { time }\end{array}$ & again & $\begin{array}{l}\text { apply- } \\
\text { may-SFP }\end{array}$ & what. & exactly & $\begin{array}{l}\text { this.year- } \\
\text { be-ADN }\end{array}$ & $\begin{array}{l}\text { necessity- } \\
\text { NoM }\end{array}$ & exist-Q \\
\hline
\end{tabular}

'If you really want to become a medical student, you may apply again next year when they recruit students, what. Why is it that (you have to become one) this year?'

In the above example, $\mathrm{B}$, in reply to A's plea, suggests that A apply again next year if A ardently aspires to become a medical student. B does so by reminding A that he has a chance next year, and solicits A's agreement. This type of the use of the discourse marker mwe typically employs the intonation drop and low pitch, signalling that the use of the interrogative is rhetorical, in the sense that the answer is straightforwardly clear and thus not required.

\subsection{Interrogative Question $\rightarrow$ Rhethorical Question of Discontent $\rightarrow$ DM of Discontent $\rightarrow$ Emphasis Marker/Objection Marker}

The development represented by the lowest branch of the polyfunctional development in Fig. 2 is the one at the center of our interest here. It also starts with Stage o (interrogative question INT, see Section 3.1 above). What follows is the stage of rhetorical questions of discontent. This can be represented by means of the following (constructed) example in English.

(43) English

Context: Son was driving drunk and crashed into a tree.

Father: What the hell were you thinking?!

19 Drama “Ceycwungwen”, episode 9, scene 49. 
Further examples come from Bulgarian and German:

(44) Bulgarian

Context: Daughter asks father for something outrageously expensive.

Father:

\begin{tabular}{|l|l|l|l|}
\hline Az ne săm milioner, & kakvo & si & văobrazjavaš! \\
\hline i not am millionaire & what & REFL & imagine.2SG.PRES \\
\hline
\end{tabular}

'I am not a millionnaire, what are you thinking?!

(45) German ${ }^{20}$

Context: A monologue.

Ich werde im Bann eines fatalistischen Elementes durch die Welt geschleift, das mich umbringt. Ich bin in einen falschen Raum gestellt, oder in ein falsches Jahrhundert—was weiß ich ? Nur fühlen kann ich's und in lichteren Momenten seh' ich's

\begin{tabular}{|l|l|l|l|l|l|l|l|l|l|l|l|l|l|l|}
\hline ... Ich & bin & in & einen & falschen & Raum & gestellt, & oder & in & ein & falsches & Jahrhundert- & was & weiß & ich? \\
\hline$\ldots$ I & am & in & a & wrong & room & put & or & in & a & wrong & century- & what & know & I? \\
\hline
\end{tabular}

'... I have been put into the wrong room or I have been born into the wrong century,

(I feel like I do not belong here), what can I say!/what do I know?'

The reason why we regard this to be an example of a rhetorical question of discontent is the way it is interpreted by native speakers, as something along the lines: "The speaker is desperate. He feels like he is forced to live in the wrong century. He is angry at his destiny. He doesn't expect an answer, since he knows he is right. It is just an outlet for his extremely negative feelings."

The next stage of development is the stage of Dis. DM whereby only the what word of the clause remains (the rest is omitted) as the following SCE example shows.

20 Digitales Wörterbuch der deutschen Sprache Treffer 28 (Deutsches Textarchiv). Kürnberger, Ferdinand: Der Amerika-Müde. Frankfurt (Main), 1855. Online: http://www.dwds .de/?view=1andqu=\%22was+weiß+ich $\% 3$ F\%22. 
(46) SCE (Smith, 1985:128)

Context: Interview with a national serviceman.

Interviewer: Suppose you were a millionaire and passed away leaving a fortune for your children. Now, you were the one to bring up this fortune, not your children, so do you think it is fair for the government to tax your children heavily on the inheritance?

NSman: (completely taken by surprise by the idea) No! That must never happen! This is your money what! The government should not tax anything at all!

In the present study we assume that sentence-final what in SCE is the result of the phonological erosion of an interrogative/exclamatory construction like "What could you say against that?!/What are/were you thinking?!/What do you expect?!"21 (among others). In other words, we assume that sentence-final what in the above example is actually a shorthand for a whole clause beginning with what, which has been drastically reduced to the extent that only the initial word is kept. Evidence for this-even though indirect-comes from the fact that in some languages the discourse marker of discontent is a fixed, idiomatic expression which has the structure of a clause beginning with the interrogative word what.

Such examples, we argue, can be treated as a more transparent manifestation of the development of interrogative what under discussion here. In Bulgarian, for instance, one way to express discontent is to use an interrogative expletive-which can have the orthography of either an exclamation mark only or an exclamation mark accompanied by an interrogative mark-used as the ending of a well formed interrogative clause. This clause can be used either before or after the host utterance. The initial word is kakvo 'what' and the verb slot is filled in by the volitional verb iskaš 'want.2SG.PRES', compare the Singapore Colloquial English example discussed above (12) and repeated-for convenience-below on the one hand and its Bulgarian counterpart, on the other.

(12) SCE (Smith, 1985: 114)

Context: The Singapore Armed Forces are generally seen as a breeding ground for "slang" and "bad language"

21 Notice that Smith $(1985: 119)$ points out in a footnote about one of the functions of sentence-final what in British English that “... Anecdotal evidence from several speakers of British English indicates that final WHAT may be used with a high rising intonation as a kind of contemptuous reminder of shared information, which might be glossed 'You're a bloody fool if you don't know that!'. Our informants associate this usage particularly with people from private schools, especially those with a military orientation." 

A: His language is terrible!
B: Army what!

(47) Bulgarian

Context: One or more than one addressee(s) present in the discoursepragmatic situation.

A:

\begin{tabular}{|l|l|l|l|}
\hline Ezikăt & $m u$ & $e$ & užasen! \\
\hline Tongue & his & is & Terrible \\
\hline
\end{tabular}

'His language is terrible!'

B:

\begin{tabular}{|l|l|l|l|l|l|l|l|}
\hline (Kakvo & iskaš, $)$ & toj & e & ot & armijata, & (kakvo & iskaš)! \\
\hline (what & want.2SG.PRES) & he & is & from & the.army & (what & want.2SG.PRES) \\
\hline
\end{tabular}

'He is from the army, what the hell did you expect!'

Notice that in Bulgarian kakvo iskaš! is a fully conventionalized discourse marker of discontent as its morpho-syntactic behavior indicates: The verb iska-šs (want-2SG.PRES) keeps its $2^{\text {nd }}$ person singular present morphological ending independent of the number of addressees (one or more than one).

A trace of the development of $\mathrm{RH}$ Dis. into Dis. DM in present-day British English is to be seen in examples like the one in the title of this article.

(48) British English

Are you the queen of England or what!

Examples like these-we propose-are the combination of what initially were two rhetorical clauses, the second of these being "what were/are you thinking?!". ${ }^{22}$ Due to high frequency of use and — subsequently-high

22 One of our referees points out the possibility for at least one more interpretation of the meaning of or what, whereby it is more like a reduction of "what are the alternatives?", cf. an example like Am I happy, or what!, where "or what" functions as an affirmation, and seems to say, "or is there something wrong with my analysis?". We absolutely agree with this interpretation of or what! when the $1^{\text {st }}$ person singular is involved either as the subject or the object of the preceding clause, as in the above example. When it comes to contexts involving $2^{\text {nd }}$ person singular as the subject or the object - cf. (48) above-an interpretation in favor of discontent appears to be more plausible. 
predictability, only the initial interrogative $w h$-element of the second clause remained, preceded by the conjunction or, and the rest of the second clause was omitted.

It turns out that rhetorical questions of discontent develop into discourse markers of discontent also in other languages. Thus the following example from colloquial French shows that sentence-final quoi can also serve as Dis. DM.

(49) Colloquial French

\begin{tabular}{|l|l|}
\hline Arrete & quoi! \\
\hline Stop & what \\
\hline
\end{tabular}

'For God's sake, stop it!'

Korean presents an interesting picture in that it has a form that is functionally ambiguous between the Dis. DM and the marker of emphasis (EMPH). The form appears as a full-fledged interrogative sentence mweya, consisting of the interrogative $m w e$, the copula $i$, and the sentence-final particle $-a$ (note that the sequence of two vowels diphthongizes into $y a) .{ }^{23}$ The form occurs as attached at the end of the sentence, thus following a regular sentential ending.

The dual function is disambiguated by the context, that is, if the form occurs after a (rhetorical) question, marked with the interrogative sentence-final particle - $a$, it signals the speaker's strong discontent, whereas it signals emphasis if it follows a declarative sentence-final particle, for example, determinative - $c i$, as exemplified in (50) and (51), respectively. ${ }^{24}$

(50) Korean (Korterm Corpus 3643$)^{25}$

Context: A is infuriated by the discovery that his military service record shows that he had neurosis during his service and is demanding the clerk $\mathrm{B}$ to erase the record. B is annoyed by the unreasonable demand by A. The argument becomes vehement and the two are about to engage in physical violence.

23 Korean allows omission of sentential arguments as long as they are recoverable from a discourse context. In the case under discussion, the sentential subject is omitted, that is, mweya ('what is (it)?') is literally '( $\mathrm{x}$ ) is what?'.

24 The discontent marker and the emphasis marker may also be differentiated by their suprasegmental features, that is, the form is realized with a rising intonation for the former, and a falling intonation for the latter.

25 The KORTERM Corpus consists of 15 million tagged words and 70 million untagged words, developed by Korea Advanced Institute of Science and Technology (KAIST). 
B:

\begin{tabular}{|l|l|l|l|l|}
\hline$i$ & acessi-ka & cikum & swulcwucengha-nun-ke-i-a & mweya? \\
\hline this & man-NOM & now & $\begin{array}{l}\text { act.out.of.drunkenness-ADN- } \\
\text { NOMZ-be-SFP }\end{array}$ & what.is.(it)? \\
\hline
\end{tabular}

'Hey, are you insanely drunk or what?' (Lit. 'Is this guy behaving out of drunkenness, what?')

(51) Korean (KORTERM Corpus 2649)

Context: The narrator describes the frog fable, in which the frog A keeps inhaling to inflate his belly to match the size of a cow as described by frog B. The narrator says with an overtone of relief that the frog A did not die.

\begin{tabular}{|l|l|l|l|l|l|l|}
\hline amwuthun & pay-ka & an & theci-n & $k e-n$ & chenmantahayng-i-ci & mweya! \\
\hline anyway & $\begin{array}{l}\text { belly- } \\
\text { NOM }\end{array}$ & not & $\begin{array}{l}\text { explode- } \\
\text { and }\end{array}$ & $\begin{array}{l}\text { NOMZ- } \\
\text { TOP }\end{array}$ & very.good.luck-be-SFP & $\begin{array}{l}\text { what. } \\
\text { is(it)! }\end{array}$ \\
\hline
\end{tabular}

'It's indeed good luck that his belly didn't pop.'

Furthermore, the following example from Korean involving an utterance of a speaker who is 'not happy with the situation and has a grudge against the interlocutor' (Koo and Rhee, 2013:77) shows that in Korean, sentence-final interrogative pronoun mwe 'what' can function as a Dis. DM).

(52) Korean (Koo and Rhee, 2013: 77)

\begin{tabular}{|l|l|l|l|}
\hline na- $n$ & caconsim-to & eps-na & mwe \\
\hline I-TOP & self-esteem-also & not.exist-SFP & $\operatorname{DM}(=$ what $)$ \\
\hline
\end{tabular}

'(Do you think that) I don't have a sense of self-esteem?' (Lit. 'Do I not even have self-esteem, what?')

Korean turns out to be an interesting example of a language where nonbound, sentence-final mwe 'what' has further de-categorialized into a suffixal sentence-final particle of discontent (SFPD). Thus, on the basis of a synchronic and diachronic study of interrogative clauses in Korean Koo and Rhee (2013) conclude that the discourse marker of discontent mwe 'what' has fused with 
the sentence-final particle (SFP) indicating interrogative, $-n a$ of a preceding interrogative clause, the result being the SFPD -nam.

(53) Korean (Koo and Rhee, 2013: 71)

Context: Said by a parent to a child who is not serious about studying.

\begin{tabular}{|l|l|l|}
\hline paywu-ese & nam-ø & cwu-nam \\
\hline learn-and & others-ACC & give-SFPD \\
\hline
\end{tabular}

'(Do you think) studying will benefit others?' [No! It will benefit you!]

Koo and Rhee (2013) offer a detailed description of how the free standing discourse marker of discontent mwe 'what' has fused into the verbal morphology of Korean.

Korean has an impressive inventory of sentence-final particles (SFPs) that appear as clusters of verbal morphology. The last slot of the SFP cluster is for sentence type indicators, such as declarative, interrogative, imperative and hortative. However, a new paradigm of SFPs is emerging in contemporary Korean, those that mark the speaker's discontent (Koo and Rhee, 2013: 70-71).

The developmental stages of the sentence-final particle -nam are diagrammatically presented as in Fig. 3 (Koo and Rhee, 2013: 78).

Stage I: Juxtaposed Interrogative Sentences ...V-na? mwe?

Stage II: Pragmaticalization of mwe -na? mwe?> -na mwe.

Stage III: SFPD

-na mwe >-nam

FIGURE 3 Developmental Stages of SFPD -nam in Korean

The development of SFPDs is rather recent in history: [T] hey are first attested in "Sinsosel". "Sinsosel," literally meaning 'new novel,' refers to the literary genre that bridges the classical novels and modern novels in Korea. Novels in this genre, numbering about 300 , were produced at the turn of the $20^{\text {th }}$ century, but most productively between 1906 and 1913. The styles characteristic of these novels were influenced by Western literary styles, including the use of colloquial language (Koo and Rhee, 2013: 73).

We propose that - due to high frequency of use-discourse markers of discontent generalize into two further markers: Emphatic markers, and general objection markers. 
3.3.1 Discourse Marker of Discontent $\rightarrow$ Emphatic Marker

Let us first take a look at emphatic markers. The following is an example of SCE sentence-final what used as a marker of emotional emphasis.

(54) SCE (Smith, 1985: 124)

Context: $\mathrm{C}$ is ill.

A: Then have you seen the doctor or not? Have ah ... What did she say? ...

B: Nothing ah?

C: I tell you the doctor sees me: I tell her everything, that's all. ... True what. They don't know what's wrong with you. You got to tell them first right?

That this development had taken place in the lexifier language, British English, prior to the foundation time of SCE becomes clear from $18^{\text {th }}$ century British English examples like (19) repeated as (55) below.

(55) British English (O'Keeffe, 1795)

Yes, it is my wish; what! Martha will convey me privately into the Castle [sic]? delightful [sic]!

Notice that it is possible to find examples dating back to a couple of decades earlier where the use of what is ambiguous between encoding discontent and emotional emphasis.

(56) British English (Griffith, 1772)

So, Mrs. Lucy, what! does your mistress want another five hundred, to refresh her lawyers, tomorrow, and has sent you to wheedle me out of it? Eh!

This should come as no surprise because contexts of such ambiguity between a historically erstwhile and a historically later function are-expectedly-to be found in the polyfunctional development of linguistic expressions.

Examples of sentence-final what functioning as a marker of emotional emphasis in Modern British English are not that easy to find, yet this use of what can still be attested in colloquial British English as (11)-repeated here as (57) - shows.

(57) Colloquial British English (Davies, 2004-; COCA)

A: No, I haven't even heard the rest of the songs. I tell you what. 
B: Yeah.

A: I'll let you listen to it, I brought it in today. Rough tape what.

In German, too, one can use was 'what' sentence-finally in order to express emphasis. It looks like the clearest examples of what used as an emphatic particle in German can be found in a nonstandard variety of the language spoken in and around Cologne, called Colognese German, where wat is the form used for 'what' instead of Standard German was 'what'.

(58) Colognese German (Sabrina Reginek, p.c.)

\begin{tabular}{|l|l|l|l|l|l|}
\hline Da & ham & wa & wat & jemacht & wat! \\
\hline There & have & we & what & made & what \\
\hline
\end{tabular}

'We've done something there, man!'

One can find examples of sentence-final what in Standard German and depending on the intonation contour, was 'what' is to be interpreted as either an appeal-for-agreement/solidarity marker (interrogative intonation contour) or as an emotional emphasis marker (exclamation intonation contour):

(59) Colloquial Standard German

\begin{tabular}{|l|l|l|l|l|}
\hline Du & glaubst & mir & nicht & was? \\
\hline You & believe.2SG.PRES & me & NEG & what \\
\hline
\end{tabular}

'You don't believe me, do you?'

(6o) Colloquial Standard German

\begin{tabular}{|l|l|l|l|l|}
\hline $\mathrm{Du}$ & glaubst & mir & nicht & was! \\
\hline You & believe.2SG.PRES & me & NEG & what \\
\hline
\end{tabular}

'You don't believe me!'

A much more interesting case of ambiguity in Colloquial Standard German is the use of sentence-final was 'what' preceded by the interjection ah! 'ah!. Such cases do not involve any differences in the intonation contour of the utterance and ah was! 'ah what!' can be interpreted either as an emphatic marker or a discourse marker of discontent. 
(61) Colloquial Standard German

A: Sie ist schwanger.

B: Sie ist nicht schwanger, ah was!

'She is not pregnant, for God's sake!/She is not pregnant, you idiot!'

Therefore, it is plausible to assume that ambiguity contexts like the above may well have served as the locus-for-change whereby the emphatic function of sentence-final was 'what' has come into existence in German. This formal identity with functional ambiguity is also attested in Korean as illustrated earlier in Section 3.3.

\subsubsection{Discourse Marker of Discontent $\rightarrow$ Objection Marker}

Finally, the other branching development that discourse markers of discontent (Dis. DM) undergo-we contend-is the development of major interest for us here, namely the one that leads to sentence-final use of what as a general objection marker.

We propose that the general objection function of sentence-final what in SCE results from generalization-which necessarily involves desemanticization, as studies of language change have repeatedly shown —of its meaning of Dis. DM: Due to the frequency of use the specific semantic component of discontent inherent in the meaning of the Dis. DM fades out so that the function of the new marker is much more general, unmarked for polarity, serving to indicate general objection to something in the discourse situation. ${ }^{26}$

(62) Singlish (Smith, 1985: 110)

Context: Discussion of student who is going overseas for one month and missing classes.

A: He'll never pass the third year.

B: It's only for one month what.

In (62), the sense expressed appears equivalent to "though", or "after all", according to native speaker informants, ${ }^{27}$ that is, serving not only to reject, see (63), but also a sense of concession or justification. In (63) and (64), the sense of objection becomes more pronounced.

26 A similar development can also be observed with intensifiers. Their erstwhile specific, strong emotional meaning component becomes weaker and less expressive over time (Heine and Kuteva, 2007).

27 Tuck Choy (personal communication). 
(63) Singlish (Smith, 1985:126)

Context: Two people trying to find their way from one building to another.

A: That way can not [sic] la.

B: Can what.

(64) Singlish (Smith, 1985:126)

Context: The Department of English Language and Literature keeps separate records on the two sections. A literature lecturer requests a file from the secretary, who gives it to him. He flips through it.

Lecturer: (virtual monotone) This is all language what.

Secretary: (great surprise, high pitch) Is it?

In (63), the speaker uses what to refute or reject the previous utterance, while in (64) what is used in rejecting the offer of the wrong file. Both such functions involve a general indication of objection by the speaker to relevant utterances or actions.

In other words, we are dealing with an unexpected phenomenon: Interrogative what has proceeded further along the development path in the replica language, $\mathrm{SCE}$, than in the model language, that is, the lexifier language, British English. Thus SCE speakers not only replicate Stage I and Stage II of that development - and thus recapitulate the whole development path in the model language but they go a step further (Stage III, with what functioning as a pragmatic particle with the general meaning of speaker's rejection of something in the context). This certainly contradicts what has been considered to be a well-established fact in contact-linguistics, namely that the language change process in the model language is - as a rule-more advanced than the one in the replica language (see Heine and Kuteva, 2005 for examples). Against the backdrop of such observations, it is really intriguing that the development of sentence-final what into a particle is much more advanced in the replica language (Singapore English) than in the model language (Colonial British English). Cases like these have been insightfully discussed in Ziegeler (2000), where they have been attributed to communicative pressures inherent to the very dynamics of the language-contact situation (hyper-grammaticalization) (cf. also Wiemer and Wälchli, 2012 for additional examples of a more advanced stage of contact-induced language change in the replica than in the model language).

\subsubsection{Theoretical Implications}

Ziegeler (2014) is crucially relevant to the development process under discussion here for yet another reason: It offers an account of language change 
developments within a comprehensive-and therefore more naturalisticsociolinguistic framework, within which language phenomena in Singapore English are analyzed. As in other language-contact situations where a politically dominant language such as English is involved, in the study of Singapore English we may very well be dealing with a bias of analysts of language depending on what their language background is. The reason for this is very understandable and it has to do with the emblematic function of language, in this case with the recognition (or appreciation) of substratist language identity in the earlier attempts to eradicate Singapore (Colloquial) English (which has colonial English as the lexifier language) altogether. Given the particular sociohistorical circumstances in Singapore, one can expect bias towards overweighting the influence of either precolonial language varieties spoken in the region (e.g. Malay, Cantonese, Hokkien), or Mandarin Chinese instead of the multifarious Chinese dialects once spoken on the island.

In some cases, the exact source of a particular construction becomes more and more difficult to trace, given the tendencies of researchers to associate a certain usage with whatever language is most familiar to them. The present study does not claim to be an exception in this regard, but at the same time, the sentence-final use of what has so far remained inconclusive, in terms of its origins, in much of the literature to date, leaving the lexifier as the most plausible source.

The reasons for this are the following: The absence of a formal similarity with any of the substrate Chinese dialects—ruling out borrowed forms-and the curious affinities with earlier functions of a similar, now archaic utterancefinal discourse marker in British English. According to Gupta (2006), the archaic, "stereotypically aristocratic" British use of sentence-final what (in Jolly good show, what?) has nothing to do with the form in use in SCE today, and Gupta believes that the orthography in SCE is misleading. However, there are clear indications that certain uses can indeed be plausibly traced to such origins: the uses in (4) and (6) above, for example, expressing appeals for agreement and mitigation, are dramatically reflective of the same functions in British English, also shown in (22) and (23) above. Such uses could well have been transferred in a situation resembling the "retentionist" contact situations described by Pietsch (2009), for example, in the development of Hiberno-English. In retentionist situations, the historically earlier functions of a grammatical item transmitted at the time of contact are retained in the replica language until the present day, not undergoing the same changes which have taken place in the lexifier since the time of contact, for example, the medial-object perfect of $18^{\text {th }}$ century British English (as in I have my dinner eaten), retained in present-day Hiberno English, as pointed out by Pietsch (2009). 
Gupta (2006) also questions the pronunciation of what in present-day SCE, suggesting that the spelling should follow the pronunciation in omitting the final $/ t /$, and represent it as wo or woh. Obviously, a more intensive study would include more details of the phonological description of the marker, but this is not within the scope of the present study. However, from personal observation of at least one native speaker, it is not entirely clear that the final $/ t /$ is unpronounced at all, even given the fact that Singaporean speakers of English often replace final voiceless plosives with glottal consonants. At the same time, the contributors to the internet chat-room postings in examples (4) and (6) had all used the form what or wat to express the functions required. A search of the entire corpus used revealed no alternative spellings whatsoever, ${ }^{28}$ in spite of attempts by various linguists in previous accounts to modify the orthography already accepted by the native speakers themselves.

Ler (2006) also discusses the discourse particles of Singapore English, but attributes little discussion to the uses of what. However, she notes that it is the fourth most frequently used discourse marker in the ICE-SIN corpus. Research on discourse markers, and especially sentence-final discourse markers, has flourished in the past ten years, one of the more recent and succinct accounts being Traugott (2016), who focuses on the diachronic rise of right-periphery "pragmatic markers" in English. Her account lists five main functions: (i) epistemic adverbs, e.g. no doubt; (ii) comment clauses, e.g. I think, (iii) retrospective contrastive final connectors, e.g. then, though, anyway, (iv) general extenders, e.g. or something, and (v) question tags, e.g., isn't it?. Many of the functions of sentence-final what may be described as retrospective contrastive final markers, and in some cases, as having a question-tag function (e.g. (4). The latter two functions appeared quite late in the history of English, according to Traugott (2016), with retrospective contrastive markers appearing as late as Late Modern English. Although Traugott's account does not commit to the explanation of either grammaticalization or pragmaticalization, it provides firm evidence for the rapid rise of numerous other discourse markers at clause-final position which were currently evolving in British English at around the time that Singapore was being colonized. Like the medial perfect of $18^{\text {th }}$ century British English, retained to the present-day in Irish English, it would not be impossible for some features of the lexifiying dialects of the colonizers to be transmitted

28 The Corpus used for these examples is the Flowerpod Corpus, a compilation of postings from internet discussion forums 2007-8. The National University of Singapore Staff Research Support Scheme and Amelyn Thompson are gratefully acknowledged for their assistance. 
in contact with the local population. The difference is that in Irish English, a transmitted feature became fossilized in the contact dialect, whereas in the case of what, a contemporary usage in British English appears to have been further generalized after the time of contact to grammaticalize beyond the stages it had reached in the lexifier language.

In the contact languages of Southeast Asia, there is little evidence of retentionist processes at work, though the evidence of an affirmative do-auxiliary in Brunei English (Deterding, 2013) might be worth investigating (the same feature is well-known in the creoles of the West Indies). The differences between such cases and the present cases are that the retentions have remained frozen in time, as it were, while the same structures in the lexifiers have grammaticalized onwards, or disappeared altogether (in the case of affirmative do). In the present study, in which the colonial functions of the time of contact are seen as not just retained but continuing to expand in the presentday contact variety, the reasons behind this are hard to answer at the present stage of research.

It may well be the case that the polyfunctionality of the Mandarin Chinese particle $m a$, for instance, has had an accelerating role in the development of SCE sentence-final what as an objection particle. Kwan-Terry (1978) points out at least three functions for Mandarin $\mathrm{ma}$. First, it can function as an interrogative particle (Kwan-Terry, 1978: 27-28): By adding $m a$ at the end of the sentence nı̌ qù it changes its meaning from "You go." to "Are you going?" (Mandarin Chinese: nı̆ qù ma?). Second, $m a$ can also be used as an emphatic marker when it occurs after the names of several persons, for instance: "[M]a is added after the naming of each person [...] as an emphatic marker, to draw attention to each person" (Kwan-Terry, 1978: 29). Third, ma can also express objection/disapproval. Thus, the Mandarin sentence tā méi kông ma is to be translated into SCE as "He's not free what" and "He's not free!" in English (Kwan-Terry, 1978: 34). In this way, it can be seen that what is serving some of the functions expressed by $m a$, or at least that there is some overlap in the functions.

In Ziegeler (2014) was reviewed a process of contact grammaticalisation in which the contact language appeared to replicate earlier historical stages evident in the lexifier itself, a process resembling replication by recapitulation. This is unlike a retentionist account as described above, in which there is no actual replication but the transmission of a feature in contact results in the feature being retained in the contact language, long after its function has disappeared from use in the lexifier, or source language. In the present case, in which a feature not only retains functions of the lexifier in contact, but further generalizes to serve functions most likely associated with substrate languages, 
the situation of what in SCE is something of a hybrid case of replication in contact. As noted earlier, it retains diachronically earlier uses, and also pre-empts in the replica language stages beyond those of the lexifier model language itself. On the basis of the above arguments mentioned in support of our hypothesis we therefore propose that an account of SCE sentence-final what as a continuation of a development process that had started in one of the nonlocal lexifier languages, British English, is more plausible than an account exclusively in terms of morphosyntactic borrowing from the local substrate varieties.

\section{4}

\section{Conclusions}

In the preceding sections we showed that in three cross-linguistically identifiable branches of the development of interrogative what (see Fig. 2), interrogative what - clauses acquire the functions of rhetorical mitigating markers (RH Mit) and mitigating discourse markers (DM Mit.); rhetorical questions expressing appeal-for-agreement/solidarity (RH AGR) and discourse markers for appeal-for-agreement/solidarity (DM AGR); and rhetorical questions expressing discontent (RH Dis.), discourse markers expressing discontent (Dis. DM), emphatic markers (EMPH) and objection markers (овJ). This observationwe propose-has very important implications for an adequate account of the rise and development of SCE sentence-final what: It makes it clear that we need not look for the source of this particle in the local non-lexifier varieties spoken in Singapore. Even though our account is fully compatible with assumptions about the possible influence from Chinese dialects such as Hokkien, Cantonese and Mandarin as reinforcing factors for the rise of sentence-final what, it is most plausible to assume that this process originated in the lexifier language, colonial British English, especially given the fact that four of the five major functions of what as a non-interrogative element were already in place in the lexifier language in the pre-contact period as well as during the foundation period of SCE.

\section{Acknowledgements}

The authors are deeply indebted to Peter Austin, R.M.W. Dixon, Bernd Heine, Ekkehard König, Lutz Marten, Ingo Plag and Ian Smith for valuable suggestions and comments. The first author thanks the Alexander von Humboldt Foundation as well as SOAS and UCL, University of London, for their generous 
support and stimulating scientific atmosphere. The second author expresses his gratitude for the support of Hankuk University of Foreign Studies.

\section{References}

Baskaran, Lohanayahi. 1988. Aspects of Malaysian English syntax. London: University College London, ms. Online: http://discovery.ucl.ac.uk/1317756/1/283105.pdf.

Beeching, Kate. 2002. Gender, Politeness and Pragmatic Particles in French. Amsterdam: John Benjamins.

Begum, Rizwana and Thiru Kandiah. 1997. Misrecognitions of variability in new varieties of English. In: Edgar W. Schneider (ed.), Englishes around the World: Studies in Honor of Manfred Görlach. Vol. II: Caribbean, African, Asia, Australasia, 189-204. Amsterdam: John Benjamins.

Butler, Sarah 1716. Irish tales: or, instructive histories for the happy conduct of life. Farmington Hills: Thomson Gale 2003. Online: http://ota.ox.ac.uk/text/5032.html.

Davies, Mark. 2004. BYU-BNC. Based on the British National Corpus from Oxford University Press. Online: http://corpus.byu.edu/bnc.

Davies, Mark. 2008. The Corpus of Contemporary American English. Online: http://cor pus.byu.edu/coca.

Deterding, David, and S. Sharbani. 2013. Brunei English: A New Variety in a Multilingual Society. Dordrecht: Springer.

Dixon, R.M.W. 2015. The grammar of English pronouns. Typescript.

Fischer, Kerstin (ed.). 2006. Approaches to Discourse Particles. Amsterdam: Elsevier.

Griffith, Elizabeth. 1772. A wife in the right. Farmington Hills: Thomson Gale 2003. Online: http://ota.ox.ac.uk/text/5110.html.

Gupta, Anthea Fraser. 1992. The pragmatic particles of Singapore colloquial English. Journal of Pragmatics 18.31-57.

Gupta, Anthea Fraser. 1994. The Step-tongue: Children's English in Singapore. Clevedon: Multilingual Matters.

Gupta, Anthea Fraser. 1998. The situation of English in Singapore. In Joseph A. Foley, Thiru Kandiah, Zhi-Ming Bao, Anthea Fraser Gupta, Lubna Algasoff, Chee Lick Ho, Lionel Wee, Ismail S. Talib, \& Wendy Bokhorst-Heng, English in New Cultural Contexts. Reflections from Singapore, 106-126. Singapore: Oxford University Press [Singapore Institute of Management].

Gupta, Anthea Fraser. 2006. Epistemic modalities and the discourse particles of Singapore. In Fischer (ed.), 244-263 (pre-print version).

Heine, Bernd and Tania Kuteva. 2005. Language Contact and Grammatical Change. Cambridge: Cambridge University Press. 
Heine, Bernd and Tania Kuteva. 2007. The Genesis of Grammar: A Reconstruction. Oxford Studies in the Evolution of Language 9. Oxford: Oxford University Press.

Herring, Susan. 1991. The grammaticalization of rhetorical questions in Tamil. In: Elizabeth C. Traugott and Bernd Heine (eds.) Approaches to Grammaticalization, Vol. I, 253-284. Amsterdam: John Benjamins.

Ho, Mian Lian. 1986. The verb phrase in Singaporean English. Melbourne: Monash University, ms.

Ho, Mian Lian and John Platt. 1993. Dynamics of a contact continuum: Singaporean English. Oxford: Clarendon Press.

Hoare, Prince. 1796. Lock and key: a musical entertainment, in two acts, as performed at the Theatre Royal, Covent-Garden. Farmington Hills: Thomson Gale 2003. Online: http://ota.ox.ac.uk/text/3822.html.

Koo, Hyun Jung and Seongha Rhee. 2013. On an emerging paradigm of sentence-final particles of discontent: A grammaticalization perspective. Language Sciences 37. 70-89.

Kuteva, Tania. 2017. Contact and borrowing. In: Ledgeway, Adam and Ian Roberts (eds.), forthc. Cambridge Handbook of Historical Syntax. Cambridge: Cambridge University Press.

Kwan-Terry, Anna. 1978. The meaning and the source of 'la' and the 'what' particles in Singapore English. RELC Journal 9/2. 22-36.

Lakshmi Bai, B. 1991. Convergence: A perspective from question words. Language Sciences, Vol. XIII/2. 197-205.

Lennox, Charlotte. 1756. The memoirs of the Countess of Berci. In two volumes. Farmington Hills: Thomson Gale 2003. Online: http://ota.ox.ac.uk/text/515o.html; http://ota .ox.ac.uk/text/5151.html.

Ler, Soon Lay Vivien. 2006. A relevance-theoretic approach to discourse particles in Singapore English. In Fischer (ed.), 149-166.

Lim, Lisa. 2007. Mergers and acquisitions: on the ages and origins of Singapore English particles. World Englishes 26.4: 446-473.

MacNally, Leonard. 1781. Sentimental excursion to Windsor. Farmington Hills: Thomson Gale 2003. Online: http://ota.ox.ac.uk/text/5131.html.

Mesthrie, Rajend. 1982. English in Language Shift. The history, structure and sociolinguistics of South African Indian English. Cambridge: University Press.

Morton, Thomas. 1800. Speed through the plough. Farmington Hills: Thomson Gale 2003. Online: http://ota.ox.ac.uk/text/5158.html.

O'Keeffe, John. 1795. Life's vagaries. Farmington Hills: Thomson Gale 2003. Online: http://ota.ox.ac.uk/text/4275.html.

Pietsch, Lukas. 2009. Hiberno-English medial-object perfects reconsidered: A case of contact-induced grammaticalisation. Studies in Language $33 \cdot 5^{28-568 .}$ 
Platt, John T. 1987. Communicative functions of particles in Singapore English. In: Ross Steele and Terry Threadgold (eds.) Language Topics: Essays in Honour of Michael Halliday, Vol. I. 391-401. Amsterdam: Benjamins.

Rhee, Seongha. 2004a. Grammaticalization and lexicalization of rhetorical questions in Korean. Studies in Modern Grammar 35. 111-139.

Rhee, Seongha, 2004b. From discourse to grammar: Grammaticalization and lexicalization of rhetorical questions in Korean. LACUS Forum 30. 413-423.

Smith, Ian. 1985. Multilingualism and diffusion: A case study from Singapore English. Indian Journal of Applied Linguistics 11/2. 105-128.

Traugott, Elizabeth Closs. 2016. On the rise of clause-final pragmatic markers in English. Journal of Historical Pragmatics 17. 26-54.

Wiemer, Björn and Bernhard Wälchli. 2012. Contact-induced grammatical change: Diverse phenomena, diverse perspectives. In: Björn Wiemer, Bernhard Wälchli, and Björn Hansen (eds.) Grammatical Replication and Borrowability in Language Contact (Trends in Linguistics. Studies and Monographs), 3-64. Berlin: Mouton de Gruyter.

Wong, Jock. 2004. The particles of Singapore English: a semantic and cultural interpretation. Journal of Pragmatics 36. 739-793.

Ziegeler, Debra. 200o. Hypothetical Modality: Grammaticalisation in an L2 dialect. Amsterdam: Benjamins.

Ziegeler, Debra. 2014. Replica grammaticalisation as recapitulation: The other side of contact. Diachronica 31/1. 106-141. 